\title{
Metaphor as Sea Creature Naming Strategy in Akan
}

\author{
Patrick Nana Wonkyi (Ajumako), Patricia Beatrice Mireku-Gyimah (Tarkwa), \\ Grace Nana Aba Dawson-Ahmoah (Accra)
}

\begin{abstract}
The paper discusses the role of metaphor in the name construction of sea creatures among Akan (Mfantse) people within the purview of onomasiology. The role of metaphor in the naming of sea creatures has been understudied. This paper is a step towards filling the gap by analyzing the role metaphor plays in constructing naming units for sea creatures. This study has a qualitative research design. Twelve (12) fishers were purposely sampled, three (3) each from four fishing towns: Anomabo, Apam, Sekondi (Sekunde) and Moree (Mowure). The data collection tool was a semi-structured interview. The paper finds that likeness between sea creatures and static and/or dynamic entities triggers names for sea creatures. It concludes that, metaphor is employed to achieve simpler forms for salient features, communicate non-codable salient features and condense multiple features in the quest to name sea creatures among the Mfantse people. Through these vital roles, a general metaphor SEA CREATURES ARE LAND ANIMALS/ENTITIES is realized. The encyclopedic knowledge, which the Mfantse people have about their environment is realized through their naming strategies. It is recommended that the linguistics of naming percepts in indigenous Akan occupations be explored further.
\end{abstract}

\section{Introduction}

Image, behavioural and functional similarities between sea creatures and static and dynamic entities trigger fish names like hawkfish (Cirrhitidae), garden eel (Heterocongridae), Anglerfish (Lophius) and boxer crab (Lybia tessellate) among English speakers say (Ureña/Faber 2010). Similarly, image, behavioural and functional similarities between sea creatures and entities in the environment trigger naming units for sea creatures among Akan (Mfantse) speakers. We can therefore say that, metaphor is instrumental in the naming of sea creatures.

The study of names has attracted the attention of scholars in anthropology and linguistics. Among them are Sarpong (1974), Obeng (1998), Agyekum (2006) and Sekyi-Baidoo (2019) who suggest that names are more than just arbitrary representations of entities among a given people. They prove that the Akan people give names to entities as a means of differentiating, recognizing and knowing the said entities. Hence, Akan names give insight into Akan culture, philosophy, thought, environment, religion and language. The naming of sea creatures is not an exception to this assertion. Creatures in the sea are named for differentiation, recognition and identification. Some of the sea creature names are grounded on features of entities in the environment. 
Fish names have been collected and discussed by archaeologists, linguists and marine biologists in Austronesian and Cree languages (Elbert 1972; Helfman/Randall 1973; Elameto 1975; Barnett 1978; Berkes/Mackenzie 1978; Akimichi/Sauchomal 1982; Randall/Egasta 1984; Tsuchida 1984). Concerning fishes from the African seas, Dobson (2004) and Kwei/Ofori-Adu (2005) discussed crabs and fishes. Dobson (2004) discussed freshwater crabs in Africa while Kwei/Ofori-Adu (2005) looked at the features of various fishes and also the names of the fishes in some local languages such as Ga, Ewe, Nzema and Mfantse.

Wijana (2018) attempts to analyze the use of metaphor for constructing animal names in Indonesian. It was discovered that in animal naming among Indonesians, the source domains exist in their environment. Wonkyi (2021) attempts to analyze the role metaphor plays in the naming of percepts and parts of percepts ranging from farm produce to household tools and machines among the Mfantse people. But, for the most part, studies on naming are silent on the role metaphor plays in the naming of dynamic and mobile entities like fishes among the Mfantse people. This study is a step towards filling that gap. It aims to show that, among the Mfantse people, metaphor is instrumental in constructing naming units for sea creatures. Consequently, this paper studies how, by using metaphor, Mfantse people map sea creatures to static and dynamic entities. It also examine how Mfantse people use metaphor as a strategy to economize the expressions used to name the sea creatures.

In section 1.1 we discuss the Mfantse dialect as one of the dialects under the Akan language. We provide a theoretical basis for the approach to metaphor in fish naming in section 1.2. The strategy used in data collection and the research design used in the study are discussed in section 1.3. The role metaphor plays in naming sea creatures among the Mfantse people is discussed in section 2. Finally, conclusions on why metaphor are employed in the naming of sea creatures and some recommendations are discussed in Section 3.

\subsection{The Akan Language and dialects}

As a linguistic entity, Akan refers to a congregation of dialects or languages in Ghana and neighbouring Cote d'Ivoire in West Africa, which have a remarkable degree of mutual intelligibility or which share a great deal of phonological, lexical and grammatical features. It can be seen as constituting a single language (currently); or which could be said to have shared a common origin, referred to, in linguistics circles, as Proto-Akan.

(Sekyi-Baidoo 2019: 27)

The Akan language has dialects that include Agona, Akuapem, Akwamu, Akyem, Asante, Assin, Bono, Buem, Denkyira, Fante, Kwahu, Twifo and Wasa, Agyekum (2010). Sekyi-Baidoo (2019) adds Breman to the various dialects of Akan. All the languages spoken by the ethnographic Akans are genetically related to the Akan language (cf. Agyekum 2012). The Akans are the largest ethnic group in Ghana. This study is based on the Mfantse dialect of Akan. In this study, the term Mfantse has been used in place of Fante for the reason that the speakers of this dialect refer to themselves as "Mfantsefo" and the dialect, Mfantse as also suggested by Abakah (1998, 2013). 
Mfantsefo or the Mfantse people occupy the southern part of Ghana, bounded on the south by the Gulf of Guinea, on the east by the Ga, on the west by the Ahanta, and on the north by the Wasa, Denkyira, Assin, and Akyem. [...] the Mfantse linguistic community includes Oguaa, Nkusukum, Abora, Ekumfi, Enyan, Gomua, Asebu, Kwamankese, Komenda, Edina, Abrem, Sekondi-Takoradi metropolis, and their satellite towns and villages.

(Abakah 1998: 95)

The Akans are predominantly farmers. They practice fish farming and crop farming specifically. Like other cultures, Akan (Mfantse) people consider names as markers of cultural identities and they communicate how they understand the environment in which they live. The names of sea creatures in this paper confirm this assertion.

\subsection{Literature Review and Theoretical Issues}

Studies have discussed fish names in various languages. Helfman/Randall (1973), for instance, looked at fish names in the Palauan language. They compared the similarities among Palauan, Yapese and Guamanian fishes and found that different names exist for fishes at different life stages and the sexes. Elameto (1975) compiled the names of Carolinian regular fishes in Saipan, Mariana Islands. Barnett (1978) collected fish names in the pacific languages. He included fish description and illustrations, and found out that the fishes are named based on many things, including how they hunt, how they eat, their colour and how they socialize with one another, among others. Berkes/Mackenzie (1978) also looked at the composition of Cree fish names that are used among the communities of eastern James Bay. They aimed to help identify species of fish precisely and access the position/place of Cree fishes in western science.

Concerning sea creatures in Africa, Dobson (2004) worked on the distribution of freshwater crabs in Africa. It was discovered that freshwater crabs are similar to their marine counterparts. Also, freshwater crabs are classified based on their size. Kwei/Ofori-Adu (2005) looked at the features and life of various fishes found in the coastal seas in Ghana. Fish names in local languages such as Ga, Ewe, Nzema and Mfantse were considered and discussed. It was discovered that the names of fishes in the mentioned languages are based on static and dynamic features of the said fishes. The present study adds to the literature on sea creatures in languages of the world.

In this study, we examine how Mfantse people construct names for sea creatures through a semasiological approach. We analyze the factors that come to play as Mfantse people construct naming units for sea creatures. We further examine why metaphor grounded in the folk knowledge of their environment is needed in the naming of sea creatures. Thus, onomasiology propounded by (Štekauer 1998; Grzega 2007; Kos 2019) and image metaphor by (Lakoff 1993; Grady 1997, 1999; Ureña/Faber 2010) are employed in this study. The onomasiology approach discusses factors that come up in the naming of natural organisms based on their folk knowledge of their environment while image metaphor explicates the kind of metaphor employed in the name construction for sea creatures as basic naming strategies.

The study is cast in the onomasiological model (Štekauer 1998; Grzega 2007). Originally, this model was considered as a model that fully accounts for the names of natural entities from the name coiners' point of view. It will serve as a background to discuss metaphor in the naming of percepts in the sea among the Mfantse people. 
The model had its shortcomings in relation to names that are grounded on metaphoric mappings so Kos (2019) applied the model to word-formation to expanded it further. Through this means, Kos suggests that the model should cover metaphor in name coinage since it is a vital tool in naming living organisms. It helps to economize naming units by remedying ineffable salient features and long descriptive names of salient features of referents. It also helps in condensing multiple features into simple naming units. In analyzing fish names we apply the constructs of this theory to prove that metaphor is vital in the construction of names for sea creatures among the Mfantse people.

According to Lakoff/Johnson (1980: 5) "The essence of metaphor is understanding and experiencing one kind of thing in terms of another". Agyekum (2010) adds that a metaphor is saying $\mathrm{X}$ is $\mathrm{Y}$ while in actual sense $\mathrm{X}$ is not $\mathrm{Y}$. In naming some sea creatures, the Mfantse people say a sea creature $(\mathrm{X})$ is equal to static and dynamic entities $(\mathrm{Y})$ while in actual sense the sea creature $(\mathrm{X})$ in question is not the entities $(\mathrm{Y})$ which they are mapped onto.

In the words of Lakoff (1993: 280) "Image metaphors are 'one-shot' metaphors: it maps only one image onto another image. They map one conventional mental image onto another." As for example, abstsir (lit. 'palm head') 'palm fruit head', we observe that the entities that are compared are $a b \varepsilon$ 'palm fruit' and tsir 'head' which contrast in actual sense but are visually similar Wonkyi (2021). For the purposes of naming, the image of a sea creature is mapped onto the image of an entity found in the environment. This is done based on the perceived resemblance between the images of the two entities being mapped. Here, the sea creatures, which map onto other entities, are target domains while the entities the fishes are mapped onto are the source domains.

Ureña/Faber (2010), Grady (1997, 1999), Lakoff (1993), and Lakoff/Turner (1989) are of the same view that, image metaphor compares the images of two percepts. However, contrary to Lakoff's suggestion that image metaphor stems from visual perception, Ureña/Faber (2010) and Grady (1999) propose that image metaphor should encompass all metaphors triggered by sensory perception and that they are based on both image and behavioural/functional mapping respectively. The Mfantse people map the images of sea creatures onto the images of other entities based on visual, auditory, tactile, gustatory and olfactory perceptions they have when they are exposed to both underlying entities in question (Ureña/Faber 2010).

This approach is a cognitive linguistic approach. Thus, it is centred on experiential reality. We solely consider the folk theory of what the sea creatures named are when we turn our attention to the metaphor that communicates them. We do not dwell on any scientific expert's ideas with respect to the sea creatures in question.

\subsection{Methodology}

This paper has a qualitative research design. This research design was chosen because it is a kind of research that allows for interaction between interviewer and interviewees. The study comprised twelve (12) fisherfolk purposely sampled, three (3) each from Anomabo, Apam (Apaa), Sekondi (Sekunde), and Moree (Mowure) in the Central Region of Ghana. These communities are selected because of the language they speak (Mfantse) and the occupation that dominates their communities (fishing). Three fisherfolk were chosen from each of the study 
communities in order to cross-check to see how uniform the data collected would be since sometimes the names of various fishes differ based on geographical location.

The interviewees comprised six (6) elderly males and six (6) elderly females. All informants have had at least 20years of experience in the buying and selling of fishes. They were as well 50 years and above. The 6:6 ratio is because the occupation under investigation is dominated by both male and female fisherfolk. These brackets of people were chosen because they know the etymology of the fish names and the factors that underpin their construction based on how the Mfantse people perceive and understand percepts in their environment and the fishes in question.

The method used to collect the data was a semi-structured interview. The fisherfolk were interviewed in a focus group from one community to another. In the interview, questions that need clarification were explained, and questions could be reframed for better understanding of the concepts. In the focus group discussion, the group was shown pictures of fishes and then allowed to tell their names. The interviews were audio-recorded. A book on fishes found along the coast of Ghana by Kwei/Ofori-Adu (2005) was consulted. Some fish names were taken from the book and some data collected were crosschecked with the book. Data were recorded, transcribed and analyzed by categorization and coding.

\section{Motivations for the use of metaphor in sea-creature naming}

In the following sections, we discuss why the Mfantse people employ metaphor in the naming of sea creatures. The naming process of sea creatures is similar to the naming of living beings in languages like English, where salient features play an important role in the naming process. Mostly, several salient features that are considered in the naming of sea creatures are too long to be expressed literally. Some also cannot be expressed in literal expression. The use of metaphor helps in naming such sea creatures with a greater economy of expression. In simpler terms, metaphor in sea creature naming helps the Mfantse people to come up with a simpler form for salient features, overcome non-codability of features and condense multiple local features into one form.

\subsection{Remedying non-codability of salient features}

In the naming of some sea creatures, the Mfantse people encounter some salient features that are not codable in Akan. These features resist literal description totally. It is arguable for example that, in Akan, coding specific experiences of taste and feel is not possible. For instance, a turning pain in the stomach of an Akan man may be described as me yamu rubu fa do, literally meaning 'my stomach has a sea tide in it'. Levinson/Majid (2014) and Kos (2019) talk about how different linguistic codability (a literal expression) is from an indirect conveyability (a metaphoric expression). They suggest that, indirect conveyability is employed when linguistic codability fails. SHAPE is a feature that resists linguistic codability in Akan.

Geometric terms like line, curve, angle, square, oval, triangle, rectangle, hexagon, and rhombuses do not have exact lexical equivalences in Akan. This must not be construed that the Akan do not conceptualize shapes. They have their own ways and means of looking at them.

(Agyekum 2003: 61) 
Wonkyi (2021) proves Agyekum's (2003) point further by discussing how the conceptualization of geometric features play a vital role in the naming of parts of percepts and percepts as a whole. It was realized that flowering and germination buds were named based on their geometric features among the Mfantse people. This proves that in Akan, shapes are expressed with descriptive terms and, sometimes, concrete entities that are similar to them in shape (i. e. metaphor). A similar strategy of naming via geometric feature is noted in fish naming. SHAPE is a salient feature that triggers names for some sea creatures. In Table 1 are varied names for sea creatures triggered by the feature SHAPE.

\begin{tabular}{|ll|}
\hline \multicolumn{2}{|c|}{ Fish names } \\
\hline 1. & poswo (lit. 'sea snake') 'pipefish' \\
\hline 2. & kstsekstse (lit. 'penis penis') 'sea lizard' \\
\hline 3. & enyiwaesia (lit. 'six eyes') 'six-spot sole' \\
\hline 4. & petcetsiksr (lit. 'vulture's occiput') 'African moonfish' \\
\hline
\end{tabular}

Table 1: Fish names triggered by SHAPE features

We note that the salient feature SHAPE triggers names in examples (1-4). The names are grounded in metaphoric mapping. These metaphors build on a one-onto-one image mapping between the fishes and the underlying entities that they allude to. Specifically, the shape of entities like snake, penis, eye and vulture's occiput serves as grounding for the naming of pipefish, sea lizard, six-spot sole and African moonfish.

Here, we observe that, the form of one domain is mapped onto the form of another domain. The domains mapped are basic images. Considering the assertions put forward, prototypically, image metaphors are conceived based on the resemblance in shape, and colour (Lakoff 1993). This metaphor is based on what is perceived visually. This kind of perception is the presiding component of embodied conceptualization system (Watt 1991). As illustrated in Figure 1, the source and target percepts share the highest degree of mental imagery.

\footnotetext{
${ }^{1}$ According to Agyekum (2010), the Akan have ways through which they communicate unspeakables in their culture. Among the countless unspeakables is the genitals. Here, we see that the fish is alluded to an unspeakable among the Mfantse people kotse 'male genital'. They therefore use the names panyinemmbisa (lit. 'elder does not ask') meaning 'its name is not new to adults', banyinbanyin (lit. 'male male') 'male like' as substitute names for the fish in question. However, some Mfantse people also call this fish suo wo kotse kon mu (lit. 'hold the neck of your male organ').
} 


\begin{tabular}{|l|c|}
\hline Source Domain & Target Domain \\
\hline 1. & posws (lit. 'sea snake') 'pipe fish' \\
\hline 2. & kstsekstse (lit 'penis penis') 'sea lizard' \\
\hline 3.
\end{tabular}

Figure 1: Metaphorical mappings in the names of fishes expressing SHAPE ${ }^{3}$

It is clear in Figure 1 that examples (1) and (2) map onto the silhouettes of a whole snake and a whole penis whereas in examples (3) and (4), it is only the shapes of spots on the back of a sole and the occiput of an African moonfish maps onto the eyes and the vulture's occiput. Those are the salient features at the perceptual level. Examples (3) and (4) are examples of a PART FOR WHOLE metaphor. This is a matter of the naming strategy at the onomasiological level.

\footnotetext{
${ }^{2}$ Some Mfantse people call the six-spot sole and its various spicies futufutu (lit. 'luxuriant') a description of how the scales look on the skin of the sole.

${ }^{3}$ All images in this article are used by permission from the following sources: Sharon Antwi-Baah: (1) ow 'snake', posws 'pipe fish' (2) kstse 'penis', kstsekstse 'sea lizard' (3) enyiwa esia 'six-spot sole', pets etsiksr 'vulture's occiput' and petzetsiksr 'African moonfish'. Questmedia: (3) enyiwa 'eye'.
} 
SHAPE is not linguistically codable in Akan, thus, to name the fishes in question according to their SHAPE, the Mfantse people employ metaphor. Describing the SHAPE literally to name the fishes in question can be employed but the suitable length of a naming unit for such fishes will be violated. The descriptive names may be too long. Thus, to make up for the non-codability of SHAPE, metaphor is employed to achieve an economical expression.

Specifically, the images of poows (lit. 'sea snake') 'pipe fish' and kotsekstse (lit 'penis penis') 'sea lizard' are mapped onto the images of snake and penis via their cylindrical shapes whilst the circular and semi-circular shapes of parts of enyiwaesia (lit. 'six eyes') 'six-spot sole' and petcetsiksr (lit. 'vulture's occiput') 'African moonfish' trigger the mapping between the said fishes and the eye and the occiput of the vulture.

Furthermore, Levinson/Majid (2014) state that there is arguably no possibility of literal expression of the sense of TASTE and SMELL in English. Kos (2019) exemplifies this assertion by sighting "miller" a kind of mushroom that smells like flour and "oyster plant", a plant which leaves a taste of oyster in the mouth as evidence to the claim. English and Akan are similar in this regard. Specific qualities of smell and taste are not lexically codable in Akan. Therefore, metaphor is employed to name fishes that are triggered by the salient FEEL. This is seen in Table 2.

\begin{tabular}{|ll|}
\hline \multicolumn{2}{|c|}{ Fish names } \\
\hline 5. & ewuraefuwaserekye4 (lit. 'ewura efuwa silk') 'smooth puffer fish' \\
\hline 6. & polatreke (lit. 'sea electricity') 'torpedo ray' \\
\hline
\end{tabular}

Table 2: Fish names triggered by salient features

The names in (5) and (6) are triggered by how the fishes in question may feel once they are touched. The smooth pufferfish feels very slippery in the hand and on the skin once they are felt whereas the torpedo ray sends electrical currents through the body once it is touched. Event images of touching the fishes in question and feeling their slippery nature and getting shocked are created to conduct the mapping between the smooth puffer fish and torpedo ray (target percepts) to silk and electricity (source percepts) respectively. Here, a metaphor does not only help to achieve economical expression. Since the specific sense of FEEL is not codable in Mfantse, the use of metaphor is the only way the Mfantse people can communicate it.

\subsection{Achieving a simpler form for salient features}

Aside from helping to find remedy for non-codable constituents in the naming of fishes among the Mfantse people, metaphor helps to achieve simpler forms for salient features that may require a multi-word literal description. Some fishes are named based on their most salient features. Let us consider the names of fishes in Table 3.

\footnotetext{
${ }^{4}$ Serekye is an Akan loan word with an English source, the English word is 'silk'.

${ }^{5}$ Latreke is an Akan loan word with an English source, the English word is 'electric'.
} 


\begin{tabular}{|ll|}
\hline \multicolumn{1}{|c|}{ Fish names } \\
\hline 7. & ewuraefuwasika' (lit. 'ewura efuwa money') 'rough triggerfish' \\
\hline 8. & pokstsks (lit. 'sea porcupine') 'spiny puffer' \\
\hline 9. & poapsnkye (lit. 'sea goat') 'red mullet' \\
\hline 10. & poegyinambowa (lit. 'sea cat') 'tiger shark' \\
\hline 11. & posemina/semin (lit. 'sea soap') 'blue/milk shark' \\
\hline 12. & poanoma (lit. 'sea bird') 'sharp-chin fliying fish' \\
\hline
\end{tabular}

Table 3: Fish names triggered by salient features

The names in examples (7-12) are names of fishes triggered by different salient features. These features identify the fishes and set them apart from their kinds. In example (7), the rough triggerfish (canthidermis maculatus) is known to have shiny spots on its body. The spots make its skin glitter. Sika, 'money', can be extended to mean gold or silver in this sense. The glittering feature of gold and silver trigger the name of the fish in question. Thus, under the salient feature GLITTER, the image of the rough triggerfish is mapped onto the image of sika 'money' among the Mfantse people to name it.

In example (8), the most salient feature of a spiny pufferfish is its SPINY SKIN. Thus, the name the Mfantse people call it is pokstsks (i. e. 'sea porcupine'). This name is metaphoric because the image of a spiny pufferfish in the sea is likened to the image of the porcupine on land. Here, there is a one-to-one image mapping between the porcupine and the spiny pufferfish. Mfantse people conceptualize the spiny puffer in the image of a porcupine because the spiny pufferfish has its skin covered with large and strong protective spines like those of a porcupine.

In example (9) poaponkye ('red mullet/goatfish') has a goat-like head with two slender barbels on the chin. The barbels of the red mullet map onto the tassel or toggles found on the chin and neck of a goat respectively. The salient feature here is the GOAT-LIKE HEAD and the BARBELS. The source (a goat) and target (goatfish) percepts share the most potent level of mental imagery (i. e. visual perception).

In example (10), the metaphor poegyinambowa 'common tiger shark' brings to mind an easily recoverable image that stems from visual perception. This metaphor evokes the dynamic event image of a common tiger fish (nocturnal) hunting for prey in the sea at night. This event image maps onto the image of a cat (also nocturnal) hunting for prey at night. Cats hunt better and are active at night because they have good night vision which helps them ambush their prey. In the same way, common tiger sharks have very good night visions thus they hunt at night. This metaphor, an event image is perceived not just as a conventional image onto another conventional image mapping. The salient feature here is NIGHT HUNTING.

\footnotetext{
${ }^{6}$ In some parts of the Mfantse towns, the smooth puffer fish is called skaakor lit. 'bites once' because of it sharp teeth. The name is as a result of its ability to use its sharp teeth to destroy nets at the least chance it gets. Thus, it is normally captured with hook and line. Ewura Efuwa is a personal name made up of two forms Ewura 'mistress' and Efuwa 'a Friday born' (cf. Sakyi-Baodoo 2019). Association by source plus the metaphoric feature sika 'money' trigger the name of the rough trigger fish.
} 
In example (11), we encounter the metaphor posemina 'milk/blue shark' triggered by the salient feature LATHER. In an actual sense, the milk/blue shark has no likeness to a soap. When the shark is being prepared for food, it lathers like a soap. The metaphor taps into a richly contoured and easily retrievable mental event image for both the soap and the fish. The basic level grounding, into which speakers of Mfantse tap has rich mental images and rich knowledge structure known to the speakers (cf. Lakoff 1993: 212; Ureña/Faber 2010: 128).

In example (12), there is a perceived resemblance between the source image (bird) and the target image (sharp-chin flying fish) concerning a specific salient feature: WINGS. The sharpchin flying fish grows enlarged pectoral fins. These pectoral fins serve as organs of flight just like the wings of a bird. These fishes use their pectoral fins to fly away from potential predators in the sea. So, in the literal sense, the sharp-chin flying fish flies with its pectoral fins and the bird also flies with its wings. Therefore, the name poanoma 'sea bird' is realized.

Finding a literal expression to name fishes in examples (7-12) based on their respective salient features WING, LATHER, NIGHT HUNTING, GOAT-LIKE HEAD and BARBELS, SPINY SKIN and GLITTER may be uneconomical for naming purposes. The Mfantse people thus rely on metaphor to capture the complex salient features and confine themselves into simple naming units as seen in Table 3.

\subsection{Condensing multiple local features}

In the naming of some sea creatures, the Mfantse people consider many local features. At the perceptual level, they map the more than one features considered on the sea creatures onto another percept which has those features considered. Examples are the Mfantse names for toadfish, sea turtle and sea snail seen in Table 4.

\begin{tabular}{|l|}
\hline \multicolumn{1}{|c|}{ Sea Creature names } \\
\hline 13. poatwer ${ }^{7}$ (lit. 'sea frog') 'toadfish' \\
\hline 14. poakyekyers8 (lit. 'sea tortoise') 'turtle' \\
\hline 15. ponwaba' (lit. 'sea snail') 'sea snail' \\
\hline
\end{tabular}

Table 4: Sea creature names triggered by multiple features

In examples (13-15), we consider the names poatwer (lit. 'sea frog') 'toadfish', poakyekyere (lit. 'sea tortoise') 'turtle', ponwaba (lit. 'sea snail') 'sea snail' respectively. Multiple features of a frog, tortoise and snail are considered in naming the fishes in examples (13-15). The name comes about as a result of image resemblance between the underlying entities in the metaphors cited. Let us consider the metaphoric mapping between a frog and a toadfish in Table 5 .

\footnotetext{
${ }^{7}$ In some parts of the coastal areas, specifically among the Kormantse people, this fish is called buanda.

8 The alternative form for sea turtle puhuruw has two forms; po 'sea' and ewur 'tortoise' based on the etymology of the word. The resulting form is written and mentioned puhuruw as a result of vowel harmony and rapid speech among the Mfantse people.

${ }^{9}$ Some dialects call this sea creature podenkye lit. 'sea waist dislocation'. Denkye is a spinal defect that is a resultant from isistent bending in a given line of work. It normally affects farmers. Some contemporary fishers also refer to the same creature as pokonko 'sea can'. Konko refers to a can with reference to the shell of the sea snail.
} 


\begin{tabular}{|l|c|c|}
\hline \multicolumn{1}{|c|}{ Physical Features } & Source (frog) & Target (toadfish) \\
\hline Colour & $\sqrt{ }$ & $\sqrt{ }$ \\
\hline Shape & $\sqrt{ }$ & $\sqrt{ }$ \\
\hline Wide lips & $\sqrt{ }$ & $\sqrt{ }$ \\
\hline Slimy skin & $\sqrt{ }$ & \\
\hline
\end{tabular}

Table 5: The metaphoric mapping between a frog and a toadfish

Table 5 shows multiple local features considered when naming the toadfish in Mfantse. Specifically, the frog-like head and wide lips of the toadfish trigger a perceived resemblance between it and a frog. The image of a toadfish is mapped onto the image of a frog under some features. Therefore, the metaphorical mapping is image or resemblance based. The term poatwer (lit. 'sea frog') 'toad fish' basically says that the fish in question is carved in the likeness of a frog. This metaphoric name falls in the domain of image metaphors because there is a one onto one image mapping between the frog and the toadfish. Let us consider in Table 6, the metaphoric mapping between the sea turtle and a tortoise.

\begin{tabular}{|l|c|c|}
\hline \multicolumn{1}{|c|}{ Physical Features } & Source (tortoise) & Target (sea turtle) \\
\hline Shell & $\sqrt{ }$ & $\sqrt{ }$ \\
\hline Tail & $\sqrt{ }$ & $\sqrt{ }$ \\
\hline Legs (fore/hind) & $\sqrt{ }$ & $\sqrt{ }$ \\
\hline Shape & $\sqrt{ }$ & $\sqrt{ }$ \\
\hline Colour & $\sqrt{ }$ & \\
\hline
\end{tabular}

Table 6: The metaphoric mapping between a turtle and a tortoise

It is noted from Table 6 that some local features are perceived to name the sea turtle. This metaphor is based on the resemblance in shape and/or colour between the sea turtle and the tortoise on land. Also, both underlying creatures have shells, tails, and legs (hind and fore). So, in the eyes of the Mfantse people, the sea turtle is a tortoise in the sea because it looks like one. In an actual sense, both creatures look alike but they are different. The structure of one domain (sea turtle) is mapped onto the structure of another domain (tortoise). Let us consider in Table 7 , the metaphoric mapping between a snail and a sea snail. 


\begin{tabular}{|l|c|c|}
\hline \multicolumn{1}{|c|}{ Physical Features } & Source (snail) & Target (sea snail) \\
\hline Shell & $\sqrt{ }$ & $\sqrt{ }$ \\
\hline Foot & $\sqrt{ }$ & $\sqrt{ }$ \\
\hline Eyes & $\sqrt{ }$ & $\sqrt{ }$ \\
\hline Lower tentacles & $\sqrt{ }$ & $\sqrt{ }$ \\
\hline Upper tentacles & $\sqrt{ }$ & $\sqrt{2}$ \\
\hline
\end{tabular}

Table 7: The metaphoric mapping between a snail and a sea snail

Here, the image metaphor is based on the likeness between the conventional images of two entities. A clear instance of image metaphors is the sea snail, which refers to a sea creature that has the likeness of a snail on land. The metaphor seen in this context is grounded on visual perception, a core part of the embodied conceptualization system (cf. Watt 1991). This metaphor is grounded in a high level of mental imagery that is shared by the source (a snail) and the target (sea snail) percepts. By employing metaphor atwer 'frog', akyekyere 'tortoise' and nwaba 'snail', the Mfantse people express multiple local features with less linguistic items to name the toadfish, sea turtle and sea snail respectively.

\section{Conclusion}

We have analyzed the role metaphor plays in constructing naming units for sea creatures among the Mfantse people. Semasiologically, the static or event image of sea creatures are mapped onto the static or event image of basic creatures or objects among the Mfantse people to name them. Metaphor is employed to remedy specific geometric and tactile features that are not linguistically codable in Akan. Sea creature names like posws 'pipe fish' and polatreke 'torpedo ray' come to mind. It also remedies salient features of sea creatures that will require a multiword expression to achieve simpler naming units. Sea creature names like pokstsks 'spiny puffer', poanoma 'sharp-chin flying fish' come to mind. It also helps to condense multiple local features into simple naming units. The names poakyekyere 'sea turtle' and ponwaba 'sea snail' are noted. These metaphors are understood to be triggered by the salient features of the various source domains (entities the sea creatures are named after) and the target domains (the sea creatures).

These naming strategies help the Mfantse people to be economic in constructing naming units for sea creatures. Looking at these specific metaphors we may conclude on a general metaphor: SEA CREATURES ARE LAND ANIMALS/ENTITIES. This study goes a long way to prove the old saying among the Mfantse people that, Abowa biara a ow asaase yi do ne saso wo роти, (literally meaning, 'Every creature on earth has its likeness in the sea' is a fact. It is recommended that the sociolinguistics and the morphosyntactic analysis of Mfantse fish names be explored in future research. 


\section{References}

Abakah, Emmanuel N. (1998): "On the question of Standard Fante". Journal of West African Languages 27/1: 94-115.

Abakah, Emmanuel N. (2013). "Vowel Replacement Patterns in the Mfantse Dialect of Akan". Journal of Universal Language 14/2: 7-51.

Agyekum, Kofi (2003). "Linguistic Relativity in Akan Cultural Terms." Journal of African Roots 1: 54-77.

Agyekum, Kofi (2006): “The Sociolinguistic of Akan Personal Names". Nordic Journal of African Studies 15/2: 206-235.

Agyekum, Kofi (2010): Akan Verbal Taboos. Accra: Ghana Universities Press.

Agyekum, Kofi (2012): "Documentation and preservation of the Akan Language". Basic Research Journal of Education Research and Review 23-37.

Akimichi, Tomoya/Sauchomal, Sabino (1982): Satawalese Fish Names. Micronesica 18/2: $1-34$.

Barnett, Gary L. (1978): "Handbook for the Collection of Fish Names in Pacific Languages". Pacific Linguistics D-14. Department of Linguistics, Research School of Pacific Studies. Canberra: Australian National University.

Berkes, Fikret/Mackenzie, Marguerite (1978): “Cree Fish Names from Eastern James Bay, Quebec". Arctic 31/4: 489-495.

Dobson, Michael (2004): "Freshwater Crabs in Africa". Freshwater Forum 3-26.

Elameto, Jesus Mareham (1975): "Carolinian names of common fishes in Saipan, Mariana Islands". Micronesica 11/1: 1-5.

Elbert, Samuel H. (1972): Puluwat dictionary. Canberra: Dept. of Linguistics, Research School of Pacific Studies, Australian National Univ. (= Pacific linguistics Ser. C 24).

Grady, Joseph (1997): Foundations of meaning: Primary metaphors and primary scenes. Berkeley: University of California Ph.D. dissertation.

Grady, Joseph (1999): "A typology of motivation for conceptual metaphor: correlation vs. resemblance". In Raymond W. Gibbs Jr./Gerard J. Steen (ed.): Metaphor in Cognitive Linguistics. Amsterdam/Philadelphia, Benjamins: 79-100.

Grzega, Joachim 2007: "Summary, Supplement, and Index for Grzega, Bezeichnungswandel." Onomasiology 8: 18-196. www1.ku.de/SLF/EngluVglSW/grzega1072.pdf [16.11.2019].

Helfman, Gene S./Randall, John E. (1973): "Palauan Fish Names". Pacific Science 27/2: $136-153$.

Kos, Petr (2019). "Metaphor and Metonymy as a means of Economy of Expression." SKASE Journal of Theoretical Linguistics 16/1. skase.sk/Volumes/JTL39/pdf_doc/11.pdf [19.03.2021].

Kwei, Eric A./Ofori-Adu, Daniel W. (2005). Fishes in the coastal waters of Ghana. Tema: Ronna Publishers.

Lakoff, George (1993): “The Contemporary Theory of Metaphor”. In: Metaphor and Thought. California: UC Berkeley: 1-48.

Lakoff, George/Johnson, Mark (1980). Metaphors We Live By. Chicago: University of Chicago Press. 
Lakoff, George/Turner, Mark (1989). More than Cool Reason: A Field Guide to Poetic Metaphor. Chicago: University of Chicago Press.

Levinson, Stephen C./Majid, Asifa (2014): "Differential ineffability and the senses". Mind \& Language 29/4: 407-427.

Obeng, Samuel G. (1998): “Akan Death-Prevention Names: A Pragmatic and Structural Analysis". Names 46/3: 163-187.

Randall, John E./Egaña, Cea A. (1984): "Native Names of Easter Island Fishes, with Comments on the Origin of the Rapanui People". Occasional Papers of Bernice Pauahi Bishop Museum $25 / 12$.

Sarpong, Peter (1974): Ghana in Retrospect. Some Aspects of Ghanaian Culture. Accra: Ghana Publishing Corporation.

Sekyi-Baidoo, Yaw (2019): Akan Personal Names. Accra: University of Ghana Printing Press.

Štekauer, Pavol (1998): An Onomasiological Theory of English Word Formation. Amsterdam: Benjamins.

Tsuchida, Shigeru (1984): "Fish Names in Yami (Imorod Dialect): Second Interim Report. Yami Fish Names: Alphabetical Index". Tokyo: Tokyo University Linguistics Papers (TULIP) 1984, 11-90.

Ureña, Jose Manuel/Faber, Pamela (2010): "Reviewing imagery in resemblance and non-resemblance metaphors". Cognitive Linguistics 21/1: 123-149.

Watt, Roderick J. (1991): Understanding vision. New York: Academic Press.

Wijana, I. Dewa Putu (2018): "Metaphors of Animal Names in Indonesian". Deskripsi Bahasa 1/1: $1-8$.

Wonkyi, Patrick N. (2021): "Metaphor as an object naming tool in the Mfantse dialect of Akan". Nordic Journal of African Studies 30/1: 21-21. 